\title{
Physiological demands of archery: effect of experience level
}

\section{Demandas fisiológicas do tiro com arco: efeito do nível de experiência}

\author{
Thiago Oliveira Borges \\ (1) https://orcid.org/0000-0002-2986-3454 \\ Alexandre Moreira ${ }^{2}$ \\ (1) https://orcid.org/0000-0002-4609-1839 \\ Reury Frank Bacurau \\ (D) https://orcid.org/0000-0003-1777-294X \\ Fernando Henrique Magalhães ${ }^{1}$ \\ (1) https://orcid.org/0000-0003-0783-6102 \\ Caroline Dario Capitani ${ }^{3}$ \\ (1) https://orcid.org/0000-0002-3466-6148 \\ Alexandre Nunes Martins ${ }^{1}$ \\ (D) https://orcid.org/0000-0002-3950-5319 \\ Luis Mochizuki \\ (1) https://orcid.org/0000-0002-7550-2537 \\ Marcelo Saldanha Aoki ${ }^{1}$ \\ (1) https://orcid.org/0000-0001-7803-6829
}

Abstract - The understanding of fatigue development during Archery competition would guide sports scientists, coaches and athletes on how to optimize the training routines of athletes from different competitive levels. This study investigated the effect of expertise level on physiological responses, during simulated archery competition (double-round 70m, 12 series, 6 arrows for an elite Brazilian Archer (EA) and a Novice Archer (NA). Ratings of perceived exertion, blood lactate and glucose, handgrip strength and electromyography were registered at the beginning, after each set from the $2^{\text {nd }}$ to the $12^{\text {th }}$ arrow and, 30 -min after the competition simulation. The EA showed a greater handgrip strength for both arms, a constant lower mean RMS value (Baseline $0.279 \mathrm{~V}$ and 12 th set $0.221 \mathrm{~V},-20.7 \%$ ), and a stable $\mathrm{MF}$ value throughout the competition (Baseline $146 \mathrm{~Hz}$ to $12^{\text {th }}$ set $140 \mathrm{~Hz}$ ). The NA showed a smaller handgrip strength, an increase in RMS after the 6th set towards the end of the competition (Baseline $0.387 \mathrm{~V}, 6^{\text {th }} 0.576 \mathrm{~V}$, and $12^{\text {th }}$ set $\left.0.720 \mathrm{~V},+46.2 \%\right)$ and a minor decrease in MF from the $6^{\text {th }}$ to the end of $12^{\text {th }}$ set $\left(2^{\text {nd }}\right.$ set $122 \mathrm{~Hz}, 4^{\text {th }}$ set $127 \mathrm{~Hz}, 6^{\text {th }}$ set $112 \mathrm{~Hz}$ and $12^{\text {th }}$ set $\left.117 \mathrm{~Hz},-4.1 \%\right)$. In summary, all the fatigue-related markers showed a mild response to the Archery competition simulation, although a greater magnitude was observed in the NA, compared to the EA. This study reported the physiologic demands of an Archery simulated competition, in an official format, allowing coaches and sport scientists to draw more confident decisions on competition strategy and training design.

Key words: Athletic performance; Exercise testing; Physical fitness.

Resumo - O entendimento da fadiga durante a competição de Tiro com Arco pode auxiliar na otimização da rotina de treinamento de atletas em diferentes niveis competitivos. Este estudo investigou o efeito do nivel de experiência do atleta sobre as respostas fisiológicas, durante competição simulada de Tiro com Arco para um atleta de elite (EA) e um arqueiro iniciante (NA). Esforço percebido, concentração de lactato e glicose sanguinea, força de preensão manual e eletromiografia foram registrados no início, após cada série e, 30-min após a simulação. O EA apresentou maior força de preensão manual para ambos braços, valor de média RMS constantemente mais baixo (Baseline 0,279Ve $12^{a}$ série 0,221V,-20,7\%), e valor de MF estável no decorrer da competição (Baseline $146 \mathrm{~Hz}$ a $12^{a}$ série $140 \mathrm{~Hz}$ ). O NA demonstrou menor força de preensão manual, aumento na RMS após a $6^{a}$ série até o final da competição (Baseline 0,387V, $6^{a} 0,576 \mathrm{~V}$, and $12^{a}$ série $0,720 \mathrm{~V},+46,2 \%$ ) e pequena diminuição na $M F$ da $6^{a}$ até o final da $12^{a}$ série $\left(2^{a}\right.$ série $122 \mathrm{~Hz}$, $4^{a}$ série $127 \mathrm{~Hz}$, $6^{a}$ série $112 \mathrm{~Hz}$ e $12^{a}$ série $\left.117 \mathrm{~Hz},-4,1 \%\right)$. Assim, todos os marcadores relacionados a fadiga apresentaram resposta discreta na simulação de competição de Tiro com Arco, com maior magnitude no NA, em comparação com EA. Este estudo apresentou as demandas fisiológicas da competição simulada de Tiro com Arco, no formato oficial, permitindo que treinadores e cientistas do esporte possam tomar decisões com maior confiança sobre estratégias de competição e treinamento.

Palavras-chave: Aptidão física; Avaliação da aptidão física; Desempenho atlético.
1 University of São Paulo. School of Arts, Science and Humanities. São Paulo, SP. Brazil.

2 University of São Paulo. School of Physical Education and Sport. São Paulo, SP. Brazil.

3 University of Campinas. School of Applied Sciences. Limeira, SP. Brazil.

Received: March 19, 2020 Accepted: July 17, 2020

How to cite this article Borges TO, Moreira A, Bacurau RF, Magalhães FH, Capitani CD, Martins AN, Mochizuki L, Aoki MS. Physiological demands of archery: effect of experience level. Rev Bras Cineantropom Desempenho Hum 2020, 22:e72276. DOl: http://dx.doi.org/10.1590/19800037.2020v22e72276

Copyright: This work is licensed under a Creative Commons Attribution 4.0 International License. 


\section{INTRODUCTION}

Archery requires the athletes to remain still and shoot an arrow to a target with accuracy ${ }^{1}$. In addition, athletes may choose to compete in different competition formats ${ }^{2}$, although it seems that official formats are preferred due to several reasons, which may include number of opponents and funding. To be successful in competition, athletes must manage several factors including fatigue, which is know as a component that may limit competitive performance in elite sport ${ }^{3}$. Therefore, a deeper understanding of the development of fatigue during an Archery competition would be of interest for sport scientists, coaches and athletes. Not only this would describe the competition demands, but also would shed light on opportunities to improve training routines and, eventually, enhance competitive performance.

The advances in sport science establish that the quantification of training variables is key to help the decision-making process during training and competition ${ }^{4}$. Nonetheless, before one starts quantifying and monitoring the training process, it is important to thoroughly understand the demands of the sport during competition not only for the highest-level athletes but also, their club level, developing counterparts. This approach might play an outstanding role on the training process from developing to high competitive level, which elite-level performance could be drawn with enhanced efficacy ${ }^{5,6}$. Therefore, this study investigated the effect of expertise level on fatigue development based on changes in physiological variables, obtained during maximal voluntary contractions performed along a simulated archery competition. The current study chose two archers to provide a contrast in the performance level: an elite archer was selected from the national Brazilian team (silver medal in the World Cup Lausanne 2014) and the novice was a club-level practitioner. It was hypothesized that indicators of the fatigue process would be less pronounced (if not absent) in an elite archer as compared to his novice, club-level counterpart.

\section{METHOD}

This study compared the physiological responses of an youth elite Archer (EA, silver medal in the World Cup Lausanne 2014; silver medal in under-18 Olympic Games Nanjing 2014; gold medal in under-18 World Cup Yankton 2015 - 16 yrs, 76kg, $182 \mathrm{~cm}-5 \mathrm{yrs}$ of experience, 2 yrs as a professional) and a Novice Archer (NA - 16 yrs, $70 \mathrm{~kg}, 171 \mathrm{~cm}-9$ months of experience as amateur) during a simulated archery competition (doubleround $70 \mathrm{~m}, 12$ series, 6 arrows). The variables were registered at the beginning, after each set from the $2^{\text {nd }}$ to the $12^{\text {th }}$ arrow and, 30 min after simulation completion. This study has been approved by the School of Arts, Science and Humanities of the University of São Paulo ethics committee under the number 54077616.5.0000.5390 and the participants were cleared about all procedures and risks involved in taking part in this study. 
The CR-10 scale ${ }^{7}$ was used to rate the perceived exertion of each effort. A drop of blood from earlobe was collected to determine lactate concentration and analyzed by YSI Sport 1500 (YSI, USA). Blood glucose concentration was determined by a portable monitor (Accutrend Roche ${ }^{a}$, Germany). Handgrip Strength was measured in both non-dominant and dominant arms. Each of the subjects performed maximum voluntary contractions (MVCs) for approximately 5 s by pressing a handgrip dynamometer (Digital Hand Dynamometer JAMAR PLUS, Petterson Medical, UK). Consistent verbal encouragement at baseline and after every 2 sets of shots was provided. EMG signals from the flexor digitorum superficialis (FDS) of the dominant forearm (both archers were righthanded) were recorded simultaneously. EMG signals from the FDS muscle were recorded with an electromyography system (EMG System do Brasil, São José dos Campos, Brazil). A pair of $\mathrm{Ag} / \mathrm{AgCI}$ surface electrodes was placed longitudinally over the belly of FDS of the right forearm. Electrode distances were $20 \mathrm{~mm}$ with input impedance being $50 \mathrm{M} \Omega$ and a gain of 1000. The reference electrode was placed in the cervical notch of the sternum. EMG data were recorded at a sampling frequency of $2000 \mathrm{~Hz}$. The EMG data associated with the MVC was passed through a 4th order Butterworth filter with a $20 \mathrm{~Hz}-500 \mathrm{~Hz}$ passband and Root Mean Square (RMS) values were calculated for each $50 \mathrm{~ms}$ time-window. The most stable 2 s interval (i.e. with the smaller coefficient of variation computed from RMS values) recorded during a given MVC was used to calculate average RMS values and Median Power Frequency (MF) values. For MF computations, the power spectrum of the raw EMG signal (2s duration) was obtained using the fast Fourier transform technique and MF was defined as the frequency that separates the power spectrum into two equal halves. Descriptive analyses were applied to evaluate the pattern of change in force, RMS and MF values along the Archery competition simulation.

\section{RESULTS}

The EA showed a greater handgrip strength for both arms compared to NA (Table 1). The handgrip strength of the dominant arm presented a stable score for the EA and a decreasing score for the NA (Baseline 80.2lbs and $12^{\text {th }}$ set $71.5 \mathrm{lbs} ;-10.8 \%$ ) (Table 1). For the non-dominant arm, a similar response was observed, with a decrement for the NA in the handgrip strength (Baseline 75.0lbs and 12 ${ }^{\text {th }}$ set 70.0lbs; 6.6\%) (Table 1). The EA showed a constant lower mean RMS value (Baseline $0.279 \mathrm{~V}$ and 12 th set $0.221 \mathrm{~V}$, $-20.7 \%$, whilst the NA incremented after the 6th set towards the end of competition simulation (Baseline $0.387 \mathrm{~V}, 6^{\text {th }} 0.576 \mathrm{~V}$, and $12^{\text {th }}$ set $0.720 \mathrm{~V}$, +46.2\%) (Figure 1). The EA showed a stable MF value as competition simulation developed (Baseline $146 \mathrm{~Hz}$ to $12^{\text {th }}$ set $140 \mathrm{~Hz}$ ). Conversely, the NA displayed a minor decrease in MF from the $6^{\text {th }}$ to the end of $12^{\text {th }}$ set $\left(2^{\text {nd }}\right.$ set $122 \mathrm{~Hz}, 4^{\text {th }}$ set $127 \mathrm{~Hz}, 6^{\text {th }}$ set $112 \mathrm{~Hz}$ and $12^{\text {th }}$ set $\left.117 \mathrm{~Hz},-4.1 \%\right)$, with a lower value at the last set when compared to EA $(\mathrm{EA} 140 \mathrm{~Hz}$ and 
NA 117Hz)(Figure 1). The blood glucose concentration was stable for both archers (EA and NA), varying in a normal euglycemic range (87 to $107 \mathrm{mg}$. $\mathrm{dL}^{-1}$ ) (Table 1). The EA presented a stable RPE score while the NA score increased towards the last set (Baseline 0 and $12^{\text {th }}$ set 5 ) (Figure 1 ). The blood lactate concentration remained close to baseline scores throughout the competition simulation for the EA (Figure 1), whereas the NA showed a greater value after the 10 th set $(1.5 \mathrm{mM}$ to $2.8 \mathrm{mM},+86.6 \%)$ (Figure 1$)$.

\section{DISCUSSION}

This study described how fatigue develops based on psychophysiological responses throughout an Archery competition simulation. Such information would provide coaches and sport scientists a broader scenario of this process. The main findings of this study confirmed the initial hypothesis that indicators of the fatigue process would be less pronounced (if not absent) in an EA as compared to the NA counterpart.

Archery requires athletes to shoot an arrow at a target, with accuracy ${ }^{2}$. When the athlete prepares for shooting, they must hold the bow and the string, using a strong hand press in both dominant and non-dominant $\operatorname{arms}^{1,2}$. Therefore, the handgrip strength seems to play an important role for shooting accuracy. This study showed that the EA presented superior handgrip strength and maintenance of handgrip strength levels throughout the entire competition simulation (Table 1), compared to the NA. Even though the superior result of the EA is not surprising, these findings corroborate the research of Squadrone et al. ${ }^{8}$. These researchers investigated international level Italian Archers presenting a more stable shooting, after performing a fatigue protocol, compared to their lower level team-mates,

Table 1. Comparison of scores between the novice and the elite archer throughout the simulated archery competition.

\begin{tabular}{|c|c|c|c|c|c|c|c|c|c|}
\hline & & Baseline & 2nd set & 4th set & 6 th set & 8th set & 10th set & 12th set & $\begin{array}{l}30 \text { min after } \\
\text { completion }\end{array}$ \\
\hline \multirow{2}{*}{$\begin{array}{l}\text { Handgrip Dominant Arm } \\
\text { (lbs) }\end{array}$} & Novice & 80.2 & 80.1 & 80.2 & 74.5 & 78.5 & 76 & 71.5 & \multirow[t]{2}{*}{-} \\
\hline & Elite & 93.9 & 93.4 & 90.7 & 92.6 & 92.7 & 101.9 & 94.7 & \\
\hline \multirow{2}{*}{$\begin{array}{l}\text { Handgrip Non-Dominant } \\
\text { Arm (Ibs) }\end{array}$} & Novice & 75.0 & 77.7 & 76.1 & 68.1 & 68.1 & 70.7 & 70.0 & \multirow[t]{2}{*}{-} \\
\hline & Elite & 91.6 & 95.9 & 86.9 & 89.0 & 90.8 & 90 & 88.8 & \\
\hline \multirow[t]{2}{*}{ RMS (V) } & Novice & 0.387 & 0.224 & 0.337 & 0.576 & 0.580 & 0.600 & 0.720 & \multirow[t]{2}{*}{-} \\
\hline & Elite & 0.279 & 0.234 & 0.249 & 0.227 & 0.234 & 0.215 & 0.221 & \\
\hline \multirow[t]{2}{*}{ Median Frequency (Hz) } & Novice & 101 & 122 & 127 & 112 & 117 & 117 & 117 & \multirow[t]{2}{*}{-} \\
\hline & Elite & 146 & 127 & 132 & 153 & 147 & 137 & 140 & \\
\hline \multirow[t]{2}{*}{ Blood Glucose (mg.dL-1) } & Novice & 104 & 99 & 102 & 105 & 104 & 102 & 107 & \multirow[t]{2}{*}{-} \\
\hline & Elite & 87 & 101 & 103 & 94 & 89 & 95 & 92 & \\
\hline \multirow[t]{2}{*}{ Lactate (mmol. $\left.\mathrm{L}^{-1}\right)$} & Novice & 1.5 & 2.9 & 2.8 & 2.7 & 2.4 & 2.3 & 2.8 & \multirow[t]{2}{*}{-} \\
\hline & Elite & 1.6 & 1.7 & 1.8 & 1.9 & 2.0 & 1.8 & 1.9 & \\
\hline \multirow{2}{*}{ RPE (A.U.) } & Novice & 0.0 & 2.0 & 3.0 & 3.0 & 4.0 & 3.0 & 5.0 & 4.5 \\
\hline & Elite & 1.0 & 2.0 & 2.0 & 2.0 & 2.0 & 2.0 & 3.0 & 3.0 \\
\hline
\end{tabular}

Note. RMS: Root-mean square; RPE: Ratings of perceived exertion. 

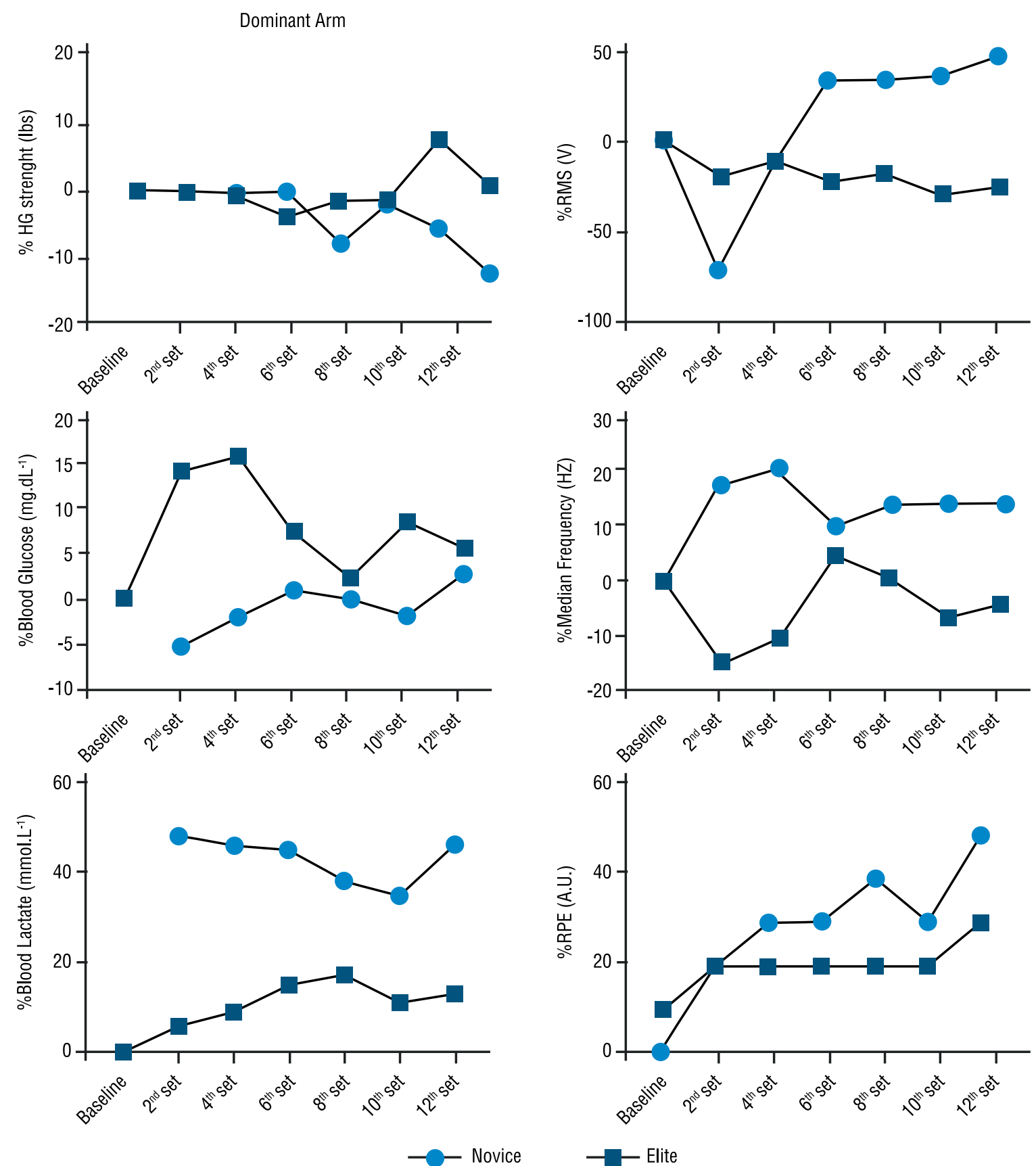

Figure 1. Normalized (\%) comparison of the investigated variables between the elite archer (open squares) and novice archer (blackfilled circles).

with a significant $(\mathrm{p}<0.05)^{8}$ correlation between International ranking and shooting stability $(\mathrm{r}=-0.65)^{8}$. Accordingly, during a competition, archers must perform a large number of shots, requiring a reliable performance.

Archery competition requires the athletes to shoot several arrows over a period of time ${ }^{2}$. It is reasonable to speculate that this sport may impose an internal load on the athletes, particularly on the less trained ones. In fact, during the simulated archery competition, the NA showed a higher RMS score associated with MVCs performed from the $6^{\text {th }}$ set of shots onwards. 
Nevertheless, these results suggest that the NA might not have been able to recruit all (or at least the most) of the FDS motoneurons during the MVCs and, as a consequence, the observed RMS value presented typical EMG amplitude parameters measured during submaximal contractions under the effect of fatigue. Traditionally, EMG amplitude increases during submaximal dynamic exercise, while it decreases during physical tasks at a maximal level of voluntary contraction ${ }^{9}$. In contrast, the low variability in RMS score shown by the EA clearly indicates a lack of fatigue-related change during the Archery competition simulation. The decrease in MF has been accepted as a sensitive parameter for muscle fatigue ${ }^{10}$. The fatigue-related events above mentioned possibly contributed to a decrease in motor unit firing frequency resulting in a shift of EMG spectrum to a lower frequency. Therefore, the pattern of changes in MF value showed by the NA strongly suggests that a fatigue process developed in the FDS muscle from the end of the 6th set to the end of a $12^{\text {th }}$ set (Figure 1). No clear decrease in MF scores occurred in the EA, suggesting that a fatigue-related mechanism was not present or not strong enough to elicit a substantial change in MF value. Collectively, these results suggest that EA possesses enhanced motor control and fatigue tolerance, compared to the NA. However, novice athletes have yet to strengthen these variables over a long-term training development process.

Archers must remain focused for most of the competition simulation. Therefore, athletes in the hypoglycemic state may have performance impairment as well as central fatigue ${ }^{11,12}$. In this study, the blood glucose level for both athletes remained within an unaltered, appropriate range. Apparently, archery competition does not affect this variable. However, this result should be carefully interpreted, since the current simulation took place after a meal (lunch) with great carbohydrate availability.

RPE was used as a practical intensity marker for this competition simulation ${ }^{7}$. For the EA, RPE score remained at the bottom of the scale during the competition simulation, characterizing the activity as low to moderate intensity. The NA presented a greater score variation, most likely due to a more pronounced fatigue. Furthermore, the session- $\mathrm{RPE}^{7}$ of the entire simulation was 3.0 and 4.5 arbitrary units for the EA and the NA, respectively. Such rating confirms the hypothesis that the competition simulation was of low to moderate intensity for both athletes in the study.

The shots in Archery require a short, dynamic muscle contraction, followed by an isometric action. Anecdotal information suggests a good shot must be executed within 10 seconds. This unlikely activates the glycolytic pathway, which could be confirmed by the low score for blood lactate concentration during the simulation, especially for the EA. Therefore, the anaerobic glycolytic system seems non-determinant in an Archery competition.

This study investigated the process of fatigue development, based on the responses of psychophysiological markers during a simulated archery competition. This approach is important for coaches and sport scientists to have a more in depth understanding of an archery competition, in an 
official format. However, the findings of this study must be interpreted considering the level of the athletes investigated. Also, the number of athletes involved in the study informs trends of physiological responses and further research to expand on these finding has yet to be developed.

\section{CONCLUSION}

In summary, all the fatigue-related psychophysiological markers showed a mild response to the simulated Archery competition. As hypothesized, a pronounced response was observed in the NA, compared to the EA. Although this was not surprising, it is important to understand the entire dynamics of an Archery competition, in an official format so that coaches and sport scientists could draw more confident decisions on competition strategies and training design.

\section{ACKNOWLEDGMENTS}

The authors would like to thank all the Brazilian Archery Confederation (CBTarco, Rio de Janeiro, Brazil) staff and athletes for their support and commitment to the study.

\section{COMPLIANCE WITH ETHICAL STANDARDS}

\section{Funding}

This research did not receive any specific grant from funding agencies in the public, commercial, or not-for-profit sectors. This study was funded by the authors.

\section{Ethical approval}

Ethical approval was obtained from the local Human Research Ethics Committee - School of Arts, Science and Humanities of the University of São Paulo and the protocol (no. 54077616.5.0000.5390) was written in accordance with the standards set by the Declaration of Helsinki.

\section{Conflict of interest statement}

The authors have no conflict of interests to declare.

\section{Author Contributions}

Conceived and designed the experiments: TOB, AM, MSA; Performed the experiments: LM, RFB, FHM, CDC, ANM, MSA; Analyzed the data: TOB, FHM, LM; Contributed reagents/materials/analysis tools: LM, RFB, FHM, CDC, MSA; Wrote the paper: TOB, AM, MSA.

\section{REFERENCES}

1. Leroyer P, Van Hoecke J, Helal JN. Biomechanical study of the final push-pull in archery. J Sports Sci 1993;11(1):63-9. 
2. World Archery. World Archery Lausanne, Switzerland2016 [Available from: https://worldarchery.org/World-Archery.

3. Fitts RH. The cross-bridge cycle and skeletal muscle fatigue. J Appl Physiol 2008;104(2):551-8.

4. Mujika I. The alphabet of sport science research starts with Q. Int J Sports Physiol Perform 2013;8(5):465-6.

5. Borrensen J, Lambert MI. The quantification of training load, the training response and the effect on performance. Sports Med 2009;39(9):779-95.

6. Roberts SP, Trewartha G, Higgitt RJ, El-Abd J, Stokes KA. The physical demands of elite English rugby union. J Sports Sci 2008;26(8):825-33.

7. Borg G. Borg's perceived exertion and pain scales. Champaign, IL: Human Kinetics Publishers; 1998.

8. Squadrone R, Rodano R, Gallozzi C, editors. Fatigue effects on shooting archery performance. ISBS-Conference Proceedings Archive; 1994.

9. Tesch PA, Dudley GA, Duvoisin MR, Hather BM, Harris RT. Force and EMG signal patterns during repeated bouts of concentric or eccentric muscle actions. Acta Physiol Scand 1990;138(3):263-71.

10. Knaflitz M, Merletti R, De Luca CJ. Inference of motor unit recruitment order in voluntary and electrically elicited contractions. J Appl Physiol 1990;68(4):1657-67.

11. Kent-Braun JA. Central and peripheral contributions to muscle fatigue in humans during sustained maximal effort. Eur J Appl Physiol Occup Physiol 1999;80(1):57-63.

12. Williams JH, Batts TW, Lees S. Reduced muscle glycogen differentially affects exercise performance and muscle fatigue. Int Sch Res Notices. 2013;2013.

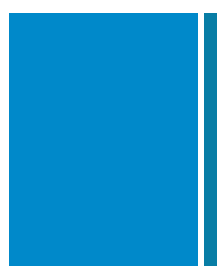

Corresponding author

Marcelo Saldanha Aoki, PhD

School of Arts, Sciences and Humanities

University of São Paulo

Av. Arlindo Bettio, 1000

São Paulo - SP, Brazil

Zip code: $03828-000$

Email:aoki.ms@usp.br 